\title{
STALL INCEPTION IN A BOUNDARY LAYER INGESTING FAN
}

\author{
D. Perovic \\ Whittle Laboratory \\ University of Cambridge \\ $1 \mathrm{JJ}$ Thomson Avenue \\ Cambridge CB3 ODY, UK \\ e-mail: dp420@cam.ac.uk
}

\author{
C. A. Hall \\ Whittle Laboratory \\ University of Cambridge \\ $1 \mathrm{JJ}$ Thomson Avenue \\ Cambridge CB3 ODY, UK \\ e-mail:cah1003@cam.ac.uk
}

\author{
E. J. Gunn \\ Turbostream Ltd \\ 3 Charles Babbage Road \\ Cambridge CB3 0GT \\ e-mail: ewan@turbostream-cfd.com
}

\section{ABSTRACT}

Jet engines with Boundary Layer Ingestion (BLI) could offer significant reductions in aircraft fuel burn compared with podded turbofans. However, the engine fans must run continuously with severe inlet distortion, which is known to reduce stability. In this paper an experimental study has been completed on a low-speed rig fan operating with a BLI-type inlet distortion. Unsteady casing static pressure measurements have been made at multiple locations during stall events. Steady-state, full-annulus area traverses have also been performed at rotor inlet and exit at a near-stall operating point. The reduction in stability caused by BLI is found to be small. It is found that with BLI the fan can operate stably despite the presence of localised regions where the rotor operating point lies beyond the stability boundary measured in clean flow. With the BLI-type distortion applied, the measured rotor incidence varies around the annulus due to non-uniform upstream velocity and swirl. The measured amplitude of unsteady casing pressure fluctuations just prior to stall is found to correlate with the circumferential variation of rotor incidence, suggesting that rotor incidence is a key variable affecting the creation and growth of flow disturbances. In regions of high incidence, disturbances resembling local flow separations are initiated. However, in regions of low or negative incidence, any disturbances decay rapidly. Full rotating stall with BLI occurs when high incidence regions are widespread enough to sustain disturbances which can propagate around the entire annulus. 


\section{INTRODUCTION}

Boundary Layer Ingesting (BLI) jet engines have the potential to reduce aircraft fuel burn by 10$15 \%$ compared with conventional podded engines [1-3]. The ingestion of low-momentum fluid from the airframe increases propulsive efficiency because this fluid can be re-energised by the fan. This reduces the wasted kinetic energy in the aircraft's wake [4]. However, the airframe boundary layer creates non-uniform flow at the fan inlet. BLI fans must therefore be designed to maintain stability while running with high levels of inlet distortion. The aim of this work is to understand how BLI alters the flow physics of the stall inception process and therefore how it affects the fan stability.

Compressor stall occurs when the mass flow rate is too low to maintain stable flow over the blades. At a critical flow coefficient, flow disturbances are created in the blade tip region, which grow into rotating stall cells. Two commonly cited routes to stall are i) the growth and propagation of small lengthscale disturbances, known as spike-type stall [5], and ii) the growth of long lengthscale oscillations in the operating point, known as modal stall [6]. Spike-type stall is the most commonly observed route in aero-engines [7] and is the stall mechanism of the rig considered in this paper.

The fluid dynamics of spike stall with axisymmetric inlet flow fields is increasingly well understood following several recent experimental and computational studies [7-10]. In [10] it was shown that high incidence values at the rotor leading edge can trigger a flow separation which then forms a radial vortex structure. This structure propagates to adjacent blades and grows in size, leading to rotating stall. The influence of inlet distortion on this process is less well understood. However, related studies have been undertaken on compressors which suffer from other types of flow non-uniformity such as non-axisymmetric tip clearance [11]. It has been found that as the spike-type disturbances propagate they can either grow or decay depending on the local rotor operating point. Full rotating stall can only occur once they have grown sufficiently large.

Previous inlet distortion studies have generally focused on either measuring and modelling the overall impact on stability margin or on understanding the flow physics near the design point. Experimental studies of the former have been carried out for decades; [12-13] are some early examples and many 
more are reviewed in [14-15]. Distortion is always found to reduce stability compared with clean flow. This leads to both a reduction in stall-point pressure rise and an increase in the stall-point flow coefficient. These tests typically consist of steady-state measurements of overall performance and employ simplified inlet distortion patterns. The physical mechanisms for the reduction in stability are therefore not yet understood. Attempts to model this distortion response, whether by the well-known parallel compressor [16] or other analytical methods [17-18], or by CFD [19], generally overpredict the reduction in stability margin.

Flow field measurements and simulations have shown that distortion leads to a large-scale flow redistribution upstream of a compressor rotor, leading to non-uniform velocity and swirl angles at its leading edge, [20-24]. In many of these studies the rotor is found to operate at high incidence in localised regions of the annulus, with a flow coefficient below the critical clean-flow value, while the machine as a whole remains stable. The incidence variations are most severe near the tip, in the same region linked to stall inception. Detailed flow field studies have previously been restricted to steady-state instrumentation at an operating point well away from instability so the precise link between these flow structures and the stability margin remains unclear.

This paper aims to improve the understanding of BLI fan stall by combining steady flow field measurements at a near-stall operating point with unsteady measurements of the stall inception process. The approach is as follows. Full area traverses of the velocity field are used firstly to quantify the change in stalling flow coefficient due to BLI. Unsteady casing pressure measurements are used to compare stall inception in clean flow and with BLI, revealing that the spike-type disturbances can either grow or decay in amplitude depending on their location relative to the distortion. The steady-state rotor incidence measurements are then linked to the observed rates of disturbance growth and decay. It is shown that regions of low incidence inhibit the growth of disturbances originating from the distorted regions of flow. This is the mechanism by which the fan can remain stable despite the presence of localised regions of instability. It is further shown that rotating stall with BLI can only occur when the high 
incidence regions are large enough in circumferential extent to allow disturbances to propagate around the full annulus without decaying.

\section{EXPERIMENTAL METHODS}

The experimental rig used for the research is a single stage, low-speed fan, shown in Figure 1. The rig was purpose built to investigate the effects of boundary layer ingestion on fan performance. The blades were designed with similar velocity triangles to a current civil transonic fan. However since the flow is incompressible and subsonic, the rig is not intended be fully representative of an engine fan. The tip clearance is relatively large and this is expected to lead to increased average tip loss relative to an engine fan, but this is not expected to qualitatively affect the physical mechanisms or the analysis presented in this paper. The rig has a long intake duct to allow the rotor to interact freely with the distorted upstream flow field. The main design parameters are shown in Table 1 and further details can be found in [24].

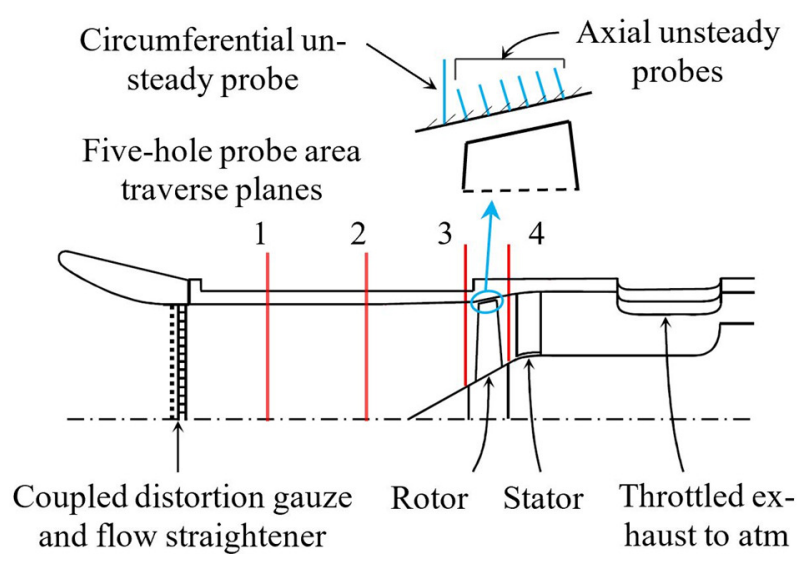

Figure 1 - Meridional view of the BLI fan rig

\begin{tabular}{|lc|}
\hline Flow coefficient $\phi=V_{x} / U$ & 0.50 \\
Stage loading coefficient $\psi=\Delta h_{0} / U^{2}$ & 0.47 \\
Rotor inlet tip $M_{\text {rel }}$ & 0.13 \\
Rotor tip Re & $2.0 \times 10^{5}$ \\
Rotor inlet tip diameter (m) & 0.48 \\
Rotor inlet hub-to-tip radius ratio & 0.30 \\
Running tip clearance (span fraction) & $0.5 \%$ \\
Number of rotor, stator blades & 20,30 \\
\hline
\end{tabular}

Table 1 - Design point flow parameters and geometry for the BLI fan rig 
The distorted inlet velocity profile used for this study was taken from previous CFD simulations of the engine intakes for the Cambridge-MIT Institute Silent Aircraft [25]. This profile resembles most BLI profiles seen in literature. It has a smooth, symmetrical velocity variation across the annulus, with a lobe of low-momentum fluid at the bottom and a region of high momentum fluid towards the top. To generate this profile in the rig, a distortion gauze was designed and installed in the intake as described in [24]. A 3D printer was used to produce the gauze as a single sheet with a precisely controlled, nonuniform porosity distribution. The resulting velocity profile measured at station 1 in the inlet is shown in Figure 2, with the rig running at its design point flow coefficient.

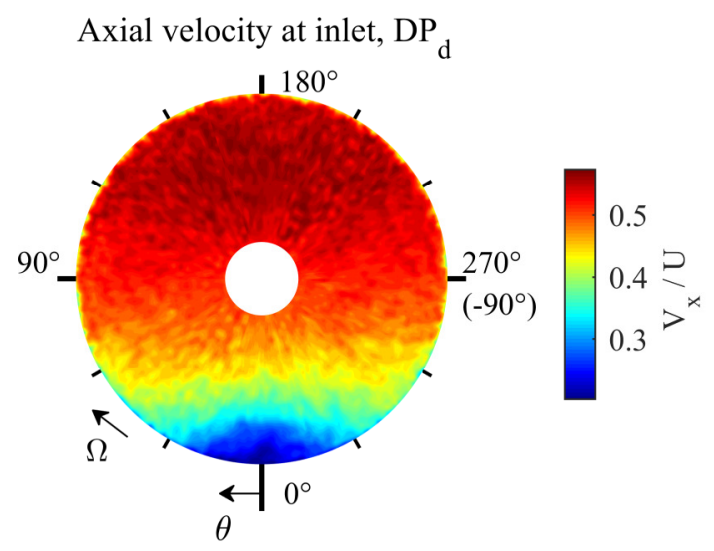

Figure 2 - Measured inlet axial velocity profile at station 1 at the design operating point and angle sign convention, adapted from [24]

Steady measurements were carried out with a five-hole pressure probe area traverse system at stations 3 and 4 (Figure 1). The probe measured the time-averaged stagnation and static pressures and the swirl and radial flow angles. The estimated uncertainties were of the order of $0.1 \%$ and $0.5 \%$ of dynamic head respectively for the pressure fields and $0.5^{\circ}$ in flow angle. The area traverse system operates within a $36^{\circ}$ sector of the rig covering a grid of around 1,000 points. Rotating the inlet distortion ten times relative to this sector allowed measurements of the full annulus flow field to be taken.

A total-to-static pressure rise characteristic measured in clean flow is shown in Figure 3. Also marked are the key operating points used for the measurements in this paper at the Design Point (DP) 
and Near-Stall $(N S)$ in both clean and distorted flow (subscripts $c$ and $d$ respectively). Note that at the operating points with distorted flow, $D P_{d}$ and $N S_{d}$, full annulus area traverses were required to determine the performance. The loss of stability due to the distortion was determined from the change in mass flow rate and was found to be $\Delta \phi=0.45-0.44=0.01$. Note that there is some uncertainty on the absolute value of $\psi_{t s}$ at $N S_{d}$ because the stator exit was not traversed.

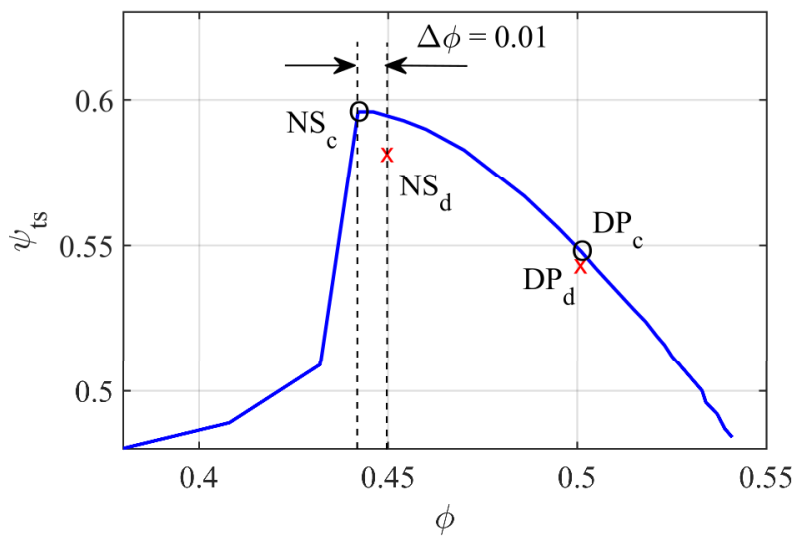

Figure 3 - Clean flow total-to-static pressure rise characteristic and key operating conditions

Unsteady measurements were used to track casing static pressure fluctuations at different points around the fan circumference. Measurements were taken using high frequency pressure probe transducers. The probes were placed in two configurations: axial and circumferential, as shown in Figure 4. The axial configuration comprised six probes placed axially along the casing at the same circumferential location, which are also shown by short blue lines in Figure 1. The circumferential configuration comprised 16 probes placed around the annulus at a plane $10 \%$ of axial chord upstream of the rotor leading edge. The spacing between the probes was $20^{\circ}$, except for one probe which was spaced $40^{\circ}$ apart from its neighbours. The position of the probes is specified by the angle $\theta$ which is defined in Figure 2. Note that angle $\theta \pm 360^{\circ}$ refers to the same circumferential location.

The sampling frequency used was $50 f_{b p}$, where $f_{b p}$ is the blade passing frequency. To reduce broadband noise in the signal, a $16.7 f_{b p}$ low pass filter was applied at the amplifier. The sampling frequency of $50 f_{b p}$ was sufficiently higher than the Nyquist frequency to avoid aliasing. 


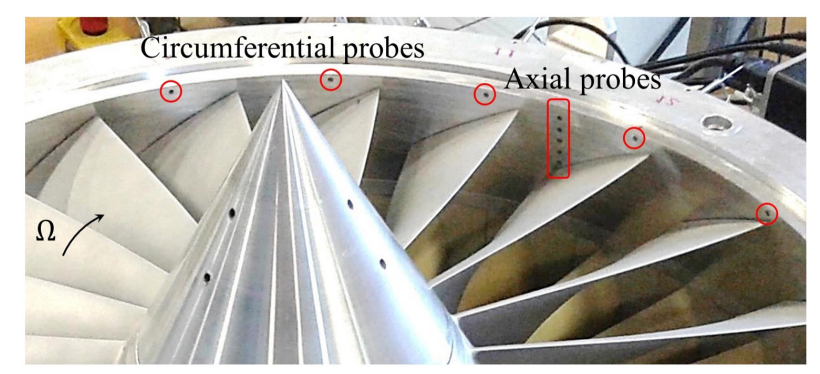

Figure 4 - Photograph of the fan rotor showing the unsteady pressure probe locations

\section{UNSTEADY DATA ANALYSIS}

Spectrograms and band power - One way of quantifying the amount by which a frequency spectrum changes is to calculate the percentage of total energy contained within a certain frequency range. Here the energy spectral density of a signal $p(t)$ is defined as $S_{p p}(f)=|\hat{p}(f)|^{2}$, where $\hat{p}(f)$ equals:

$$
\hat{p}(f)=\int_{-\infty}^{\infty} e^{-2 \pi i f t} p(t) d t
$$

The fraction of fluctuating energy contained within a certain frequency range can therefore be computed as:

$$
\frac{\Delta E\left(f_{1}, f_{2}\right)}{E}=\frac{\int_{f_{1}}^{f_{2}}|\hat{p}(f)|^{2} d f}{\int_{0}^{\infty}|\hat{p}(f)|^{2} d f}=\frac{\int_{f_{1}}^{f_{2}}|\hat{p}(f)|^{2} d f}{\int_{0}^{\frac{1}{2} f_{s}}|\hat{p}(f)|^{2} d f}
$$

This parameter is used to compare the frequency spectra of results obtained from different probe locations and hence see the effect of the BLI distortion on the size of disturbances at different positions.

Standard deviation of pressure signal p'- The measured pressure signal can be written in the form $p=\bar{p}+p^{\prime}$, where $\bar{p}$ is the time averaged static pressure at a given $\theta$ location and $p^{\prime}$ is the unsteady fluctuation. The fluctuations can be characterised quantitatively by considering the variance of the measured pressure waveform:

$$
\operatorname{Var}(p)=\sigma_{\mathrm{p}}^{2}=\overline{(p-\bar{p})^{2}}=\overline{p^{\prime 2}}
$$


The standard deviation, $\sigma_{p}=\left(\overline{p^{\prime 2}}\right)^{1 / 2}$ is a measure of the average magnitude of the pressure fluctuation $p^{\prime}$. This will be used to compare the overall level of unsteadiness in the pressure signals at different locations and instances.

\section{CLEAN FLOW STALL}

Unsteady casing static pressure signals recorded at the design point in clean flow, $D P_{c}$, were regular and showed no sign of disturbances. A pressure contour plot based on the axial unsteady measurements is presented in Figure 5. The measurements from the five transducers have been interpolated in a direction parallel to the rotor chord line. The flow is as expected at the design point - the pressure surface of each blade has higher pressure than the suction surface, showing that the blade is loaded and that the passages are unblocked. The line of low pressure extending along the blade passage indicates the trajectory of the tip leakage vortex core. This is sensitive to any disturbances [10] so the repeating pattern is another sign that the rig is operating at a stable condition.

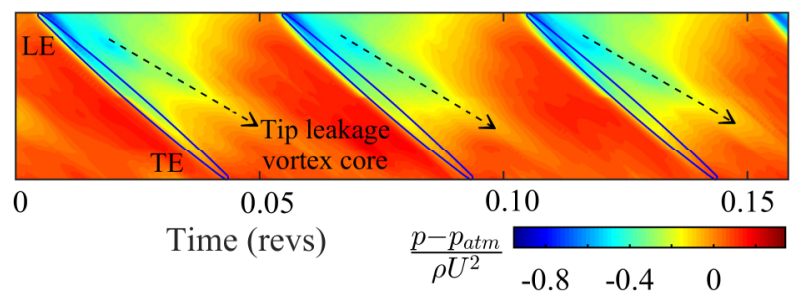

Figure 5 - Contour of casing static pressure at $D P_{c}$

Stall in clean flow is triggered by closing the rig throttle just slightly when it is operating at the last stable operating point prior to stall, $N S_{c}$. One example of a stall event in clean flow is presented in Figure 6. To make the disturbances more discernible, in the lower plot the original signal has been lowpass filtered to cut off the blade passing frequency.

Figure 6 shows initially identical pressure waveforms which become disturbed during the stall inception process. The red arrows show the size of the reference pressure $\rho U^{2}$. One of the first disturbances occurs at "A" in the form of a small downwards spike. According to [10] this is characteristic of a flow separation that has occurred in the blade tip region. Once created, it either grows in size and intensity as it moves around the annulus, or decays. In this case, the disturbance appears to decay 
initially. However, instead of vanishing, it is followed by a new disturbance which appears at "B". The disturbance at " $\mathrm{B}$ " further develops as it moves around the annulus at a speed of approximately $0.56 \Omega$, which is a typical speed of rotation for a stall cell. Within two rotor revolutions, it grows into a fully developed rotating stall cell "C", i.e. a stall cell which does not grow further in the circumferential direction. The entire process of stall inception is rapid and full rotating stall develops within 3-4 rotor revolutions of the appearance of the first disturbance.

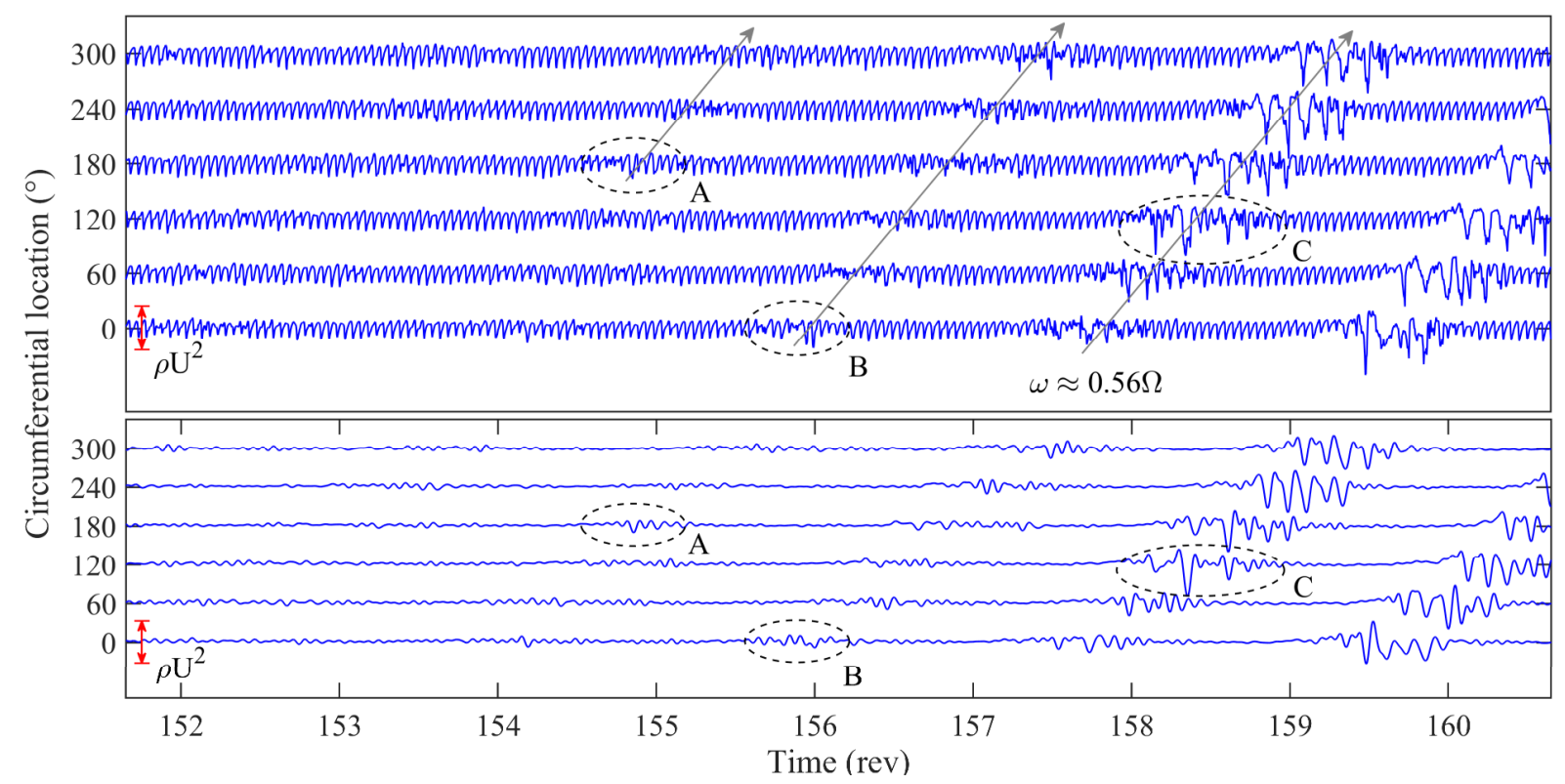

Figure 6 - Stall inception in clean flow: raw signal (above), low pass filtered signal at $90 \% f_{b p}$ (below)

The spectrogram of a signal from one of the circumferential pressure probes is shown in Figure 7. The analysis reveals that the dominant components in the pre-stall signal are at frequencies that correspond to the blade passing frequency and its higher harmonics. After the rig stalls at time $t \approx 150$ revs, additional energy appears at a broad range of frequencies. In particular, there is increased content at frequencies $f<0.5 f_{b p}$, due to the long length-scale, slow-moving disturbances which are present in stalled signal. Note that the instant of stall inception is a well defined vertical line near 150 revs; this will later be contrasted with the behaviour when BLI is present. 


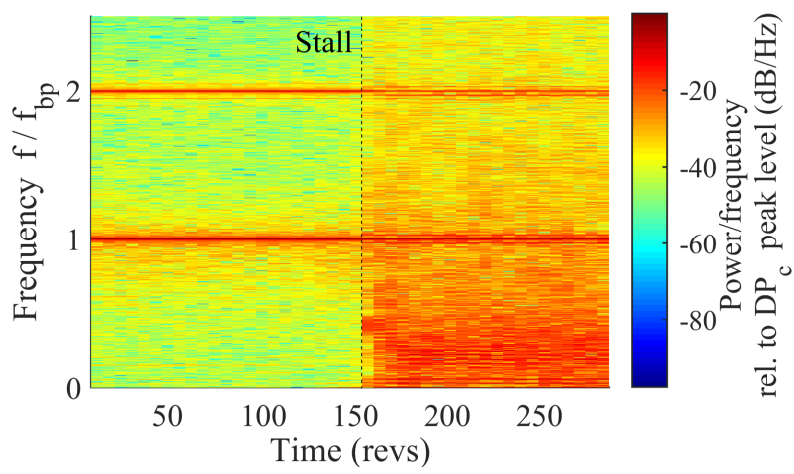

Figure 7 - Spectrogram of a casing static pressure signal around a stall event

The cumulative energy content of the signal in Figure 7 is calculated and shown in Figure 8. The plot confirms that most of the energy in the unstalled signal is at $f_{b p}$ and its higher harmonics. The energy contained at the blade passing frequency, $f_{b p}$, and its second harmonic, $2 f_{b p}$, together account for approximately $90 \%$ of the total energy of the signal. After stall occurs, noise is created which disturbs the regular blade passing signal. This has several effects. Firstly, the total fluctuating energy content increases by around $120 \%$ of its unstalled value indicating that the flow has become more unsteady. Most of this energy content, approximately 55\% of the total energy of the stalled signal, is at frequencies lower than $0.5 f_{b p}$. In addition, unlike the unstalled case in which the energy is contained at discrete frequencies, the energy of the stalled signal is distributed across a range of frequencies. The amplitude of the blade passing components is reduced after stall due to the reduction in blade loading. Figure 8 also shows an intermediate line calculated over a short interval of five revolutions during the stall inception process. This shows that during stall inception fluctuations are present at frequencies $f<f_{b p}$, a result which is used later to understand the inception process with BLI. 


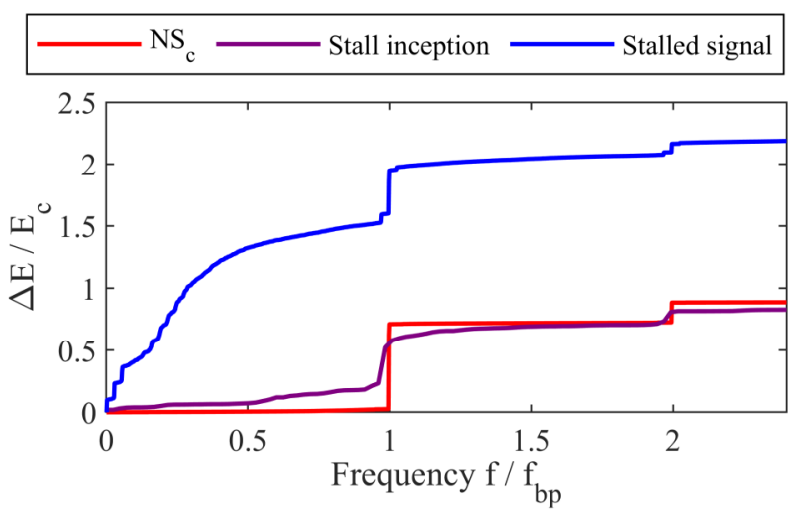

Figure 8 - Cumulative energy content of a casing pressure signal before, during and after stall. Value at frequency $f$ shows total energy in the range $[0, f]$.

Fast Fourier transform analysis of one of the circumferential signals is shown in Figure 9. It shows that energy content at $0.70 f_{b p} \leq f \leq 0.90 f_{b p}$ appears as stall is approached at $N S_{c}$ and increases further during stall inception. As the stall cells develop, disturbances of longer length scale form and these give rise to energy at $f<0.5 f_{b p}$.
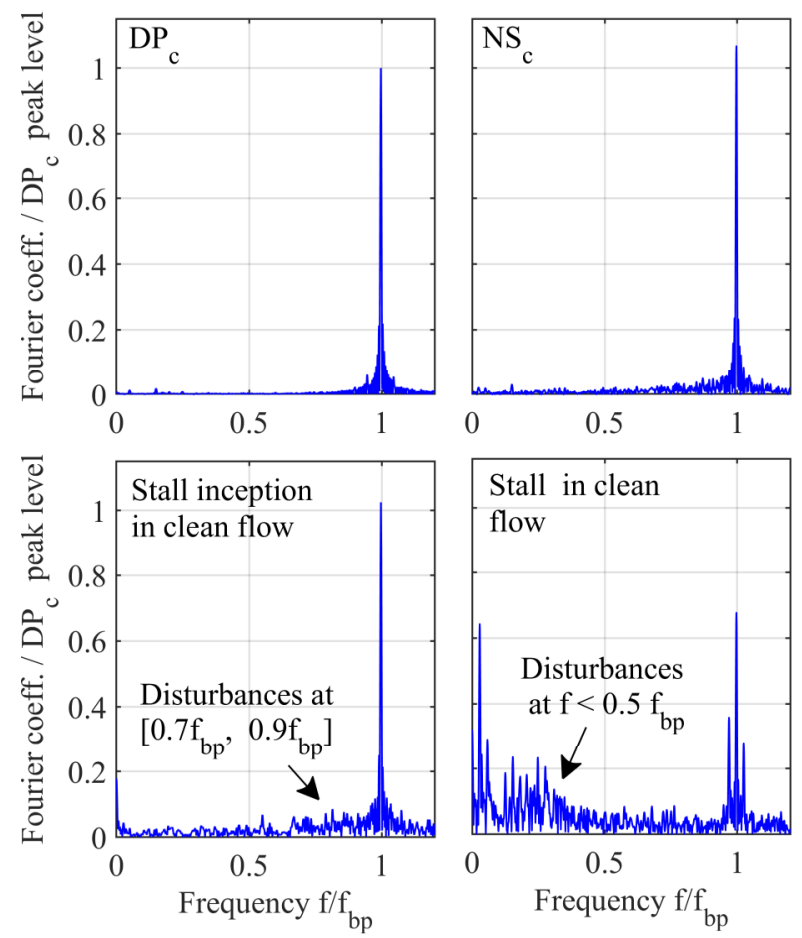

Figure 9 - Fourier transform from pressure transducers at one of the circumferential locations 


\section{UNSTEADY MEASUREMENTS IN BLI}

\section{Design Point}

Spectrograms of signals at four different circumferential locations, $\theta=\left\{-50^{\circ}, 30^{\circ}, 70^{\circ}, 150^{\circ}\right\}$, are presented in Figure 10 for the rig running at the design point with BLI inlet flow $D P_{d}$. Although the signals at $\theta=\left\{-50^{\circ}, 30^{\circ}, 70^{\circ}\right\}$ are all in the region of low momentum fluid, the flow behaviour at these locations is quite different. The first probe the blades encounter as they leave the region of high momentum fluid is at $\theta=-50^{\circ}$. The signal at this location is dominated by energy at the blade passing frequency and higher harmonics, which is characteristic of operation in clean, undisturbed flow (cf. Fig. 7). Moving further around the annulus, at $\theta=30^{\circ}$, the signal contains significant disturbances at broadband frequencies, particularly within the frequency range $0.7 f_{b p} \leq f<f_{b p}$.

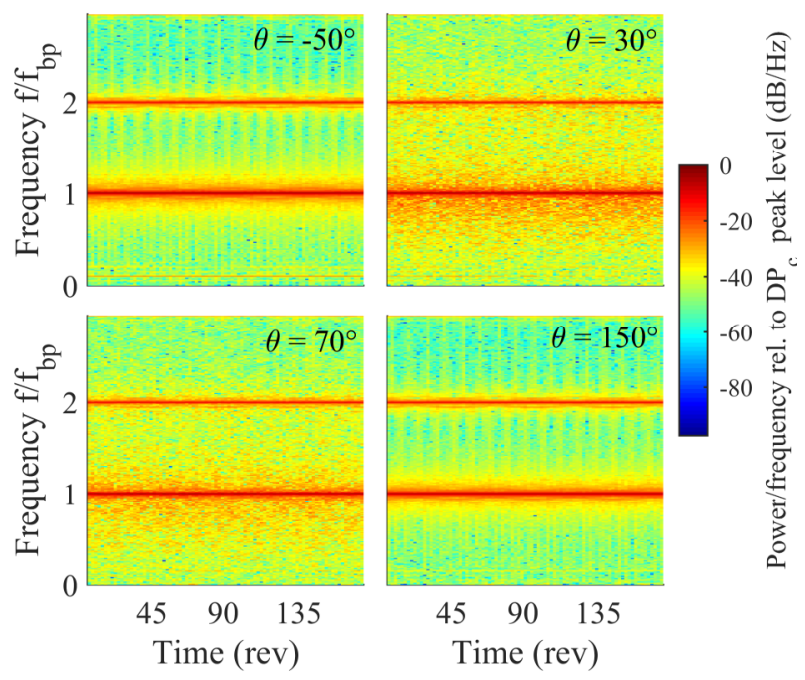

Figure 10 - Spectrograms of casing static pressure signals at $D P_{d}$

These frequencies were observed just prior to stall inception in clean flow, where they appeared about two rotor revolutions before the formation of a rotating stall cell. However in the distorted flow case, the rig operates stably even though more severe disturbances are present around approximately $15 \%$ of the circumference (shown later in Figure 13). The frequency content at $\theta=70^{\circ}$ is similar to that at $\theta=30^{\circ}$, but at $\theta=150^{\circ}$ the disturbances in the range $0.7 f_{b p} \leq f<f_{b p}$ have been eliminated. By this position the blades have moved into the region of higher momentum fluid. 


\section{Stall Inception}

When the rig is throttled from $D P_{d}$ to $N S_{d}$, the percentage of the circumference in which the casing static pressure signals are disturbed was found to increase. Stall inception in distorted flow was recorded in the same way as in clean flow: the rig was throttled slightly from $N S_{d}$ to cause instabilities and thus trigger the stall inception. In order to examine the stall inception process in detail, all 16 unsteady probes were recorded simultaneously.

A stall event in distorted flow is shown in Figure 11 (note that the plot shows only a small fraction of the recorded signal). Time is set to $t=0$ when a quasi-fully-developed rotating stall cell propagating around the full annulus forms. Visual examination of the casing static pressure waveforms shows that the most disturbed signals prior to stall inception $(t<-8 \mathrm{rev})$ are those measured at $30^{\circ} \leq \theta \leq 110^{\circ}$. Outside this region, the static pressure field is virtually unaffected by these disturbances. The first sign of a large disturbance appears at $t \approx-8.2$ revs, when a spike at " $D_{1}$ " appears. The growth and decay of this disturbance as it propagates around the annulus is labelled in the figure. The spike propagates without decay through the already disturbed regions and at $\theta=150^{\circ}$ it reaches its peak amplitude. Further around the annulus the spike is attenuated and at $\theta=250^{\circ}$ there is no sign of the disturbance. About 1 rotor revolution later, a new disturbance emerges at " $D_{2}$ ". This time it is initiated at an earlier circumferential location. It grows until $\theta=170^{\circ}$ then decays as in the previous case. The disturbance observed at " $D_{3}$ " is very similar to the previous two. It is initiated at an earlier circumferential location and propagates further around the annulus, up to $\theta=250^{\circ}$ where a small spike is recorded, but then also disappears. Eventually, a disturbance that is capable of growing into a stall cell is created at " $D_{4}$ ". It persists as it propagates around the annulus and grows up to $\theta=250^{\circ}$ where a spike of high intensity is recorded. The spike then decays but it is still apparent when it returns to its point of initiation at $\theta=$ $10^{\circ}$, having completed a full revolution of the annulus. Its amplitude at this position is now greater than one revolution previously. It continues to rotate and, although still subject to the same growth and decay processes, quickly develops into a full rotating stall cell. 


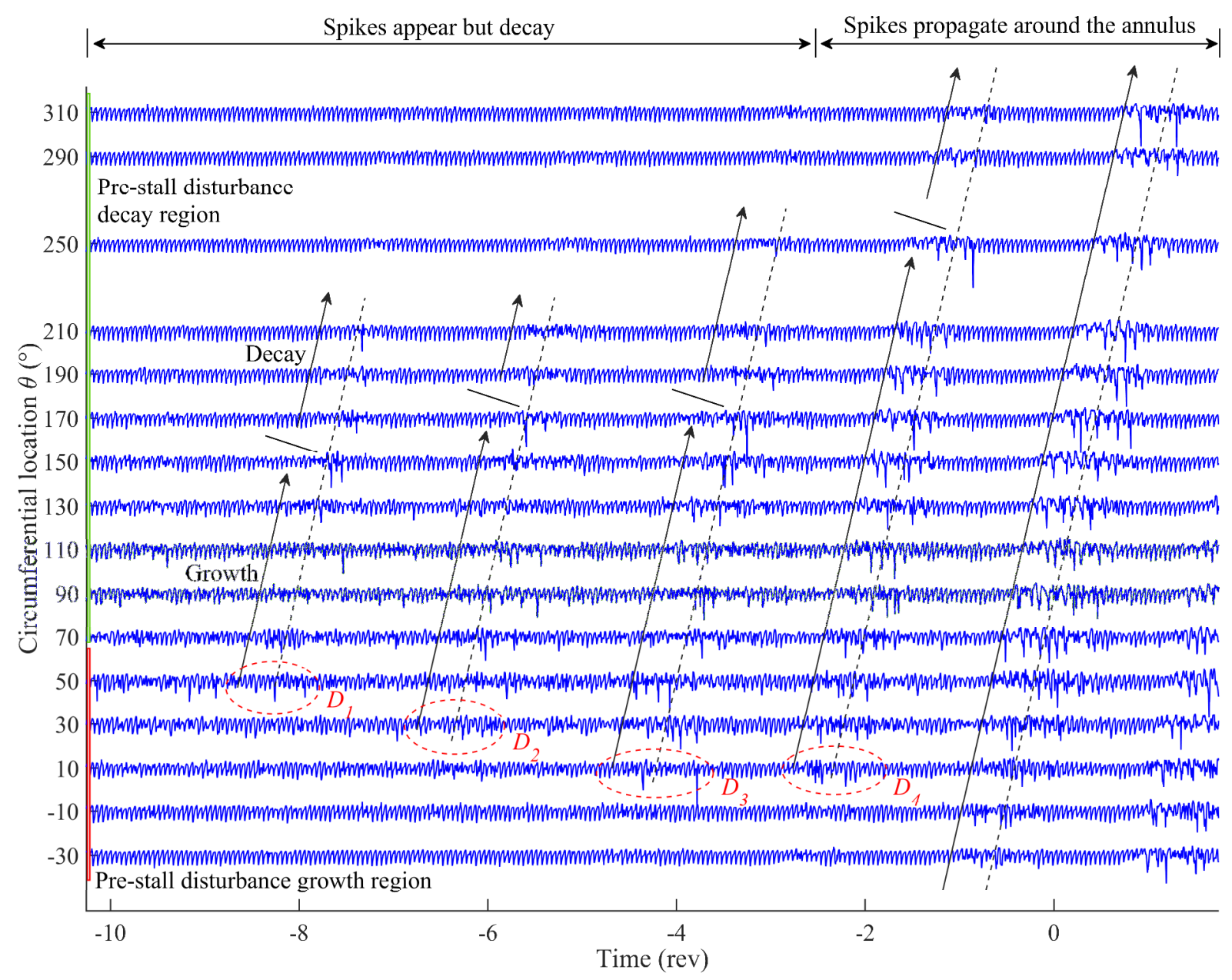

Figure 11 - Pressure waveforms, stall inception at $N S_{d}$. Dashed lines show propagations of spikes.

A similar stall event is analysed from a frequency perspective in Figure 12. The plot shows spectrograms at four circumferential locations, $\theta=\left\{-50^{\circ}, 30^{\circ}, 110^{\circ}, 210^{\circ}\right\}$. The rig is initially running at a stable operating point and stall is initiated at time $t \approx 100$ revs. Prior to stall the signals are similar to those in Figure 10. Disturbances in the range $0.7 f_{b p} \leq f<f_{b p}$ are recorded at $\theta=\left\{30^{\circ}, 110^{\circ}\right\}$, while the casing static pressure signals at $\theta=\left\{-50^{\circ}, 210^{\circ}\right\}$ are free from substantial irregularities and appear the same as in clean flow (Figure 7). The point of stall inception is less clearly defined than that in clean flow. Disturbances at $f>0.5 f_{b p}$ appear first and the low frequency, long length-scale content appears several revolutions later. This is consistent with the behaviour in Figure 11 where small disturbances undergo cycles of growth and decay before full stall develops. Post-stall, all of the signals contain energy at low frequencies. In this condition, the signals are dominated by the large rotating stall 
cell and the spectrograms at all circumferential locations become similar. In the initially disturbed signals, low frequency content is concentrated at frequencies $f>0.7 f_{b p}$, whereas after stall inception, disturbances within the range $f<0.5 f_{b p}$ become the most pronounced.

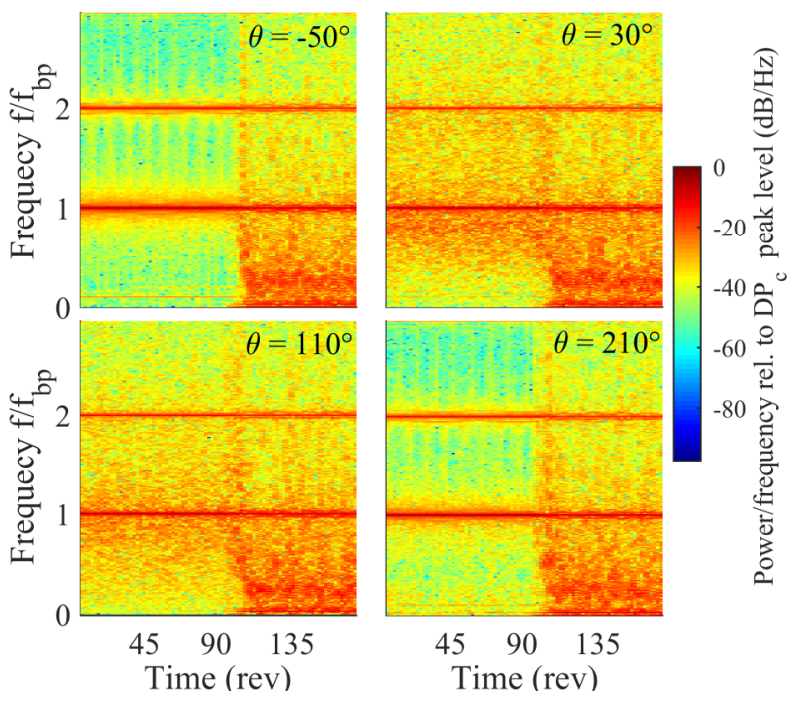

Figure 12 - Spectrograms of casing static pressure signals around a stall event in distorted flow

These findings, together with those from the section on clean flow stall, suggest that disturbances in the frequency range $0.7 f_{b p} \leq f<f_{b p}$ are key to stall inception. When content at these frequencies appears in the clean flow case, the fan stalls within approximately two rotor revolutions. In the distorted case, disturbances at these frequencies are continuously present in the region of low momentum fluid. When such disturbances propagate around the entire annulus, the fan stalls.

A function that quantifies energy content as a function of the circumferential location $\Delta E\left(\theta, 0.7 f_{b p} \leq f \leq 0.9 f_{b p}\right)$ can be used to examine the changes in the relevant energy content at the four operating points: $D P_{c}, N S_{c}, D P_{d}$ and $N S_{d}$. This frequency interval was chosen instead of $0.7 f_{b p} \leq$ $f<f_{b p}$ simply to avoid interference of the blade passing signal. This function is plotted in Figure 13, normalised by the energy contained in the same frequency range when the fan is operating at $N S_{c}$. Also plotted in Figure 13 is the variation in rotor incidence at $75 \%$ span determined from the steady traverse measurements at station 3 . The incidence values shown are relative to the inlet flow angle at stall in clean flow. Therefore, angles above zero indicate regions of the annulus where the incidence is greater Copyright $(2015$ by ASME 
than that required to cause stall in clean flow. In addition, Figure 13 shows the standard deviation of the pressure signal, $\sigma$.

At the design point in clean flow, $D P_{c}$, the value of $\Delta E(\theta)$ is negligible compared to the energy levels at the other three operating points, as expected. At $N S_{c}$ the average energy level increases, as expected. However the levels of $\Delta E$ and $\sigma$ were found to vary with circumferential location despite the lack of inlet distortion. The precise reason for this cannot be determined directly, but it is likely to be due to other sources of non-axisymmetry in the flow field such as a slight eccentricity in the rotor casing and some non-axisymmetry in the inlet and exhaust geometries. In eccentric compressors, irregularities that appear in the blade passing signal at the operating point close to stall are more pronounced in the region of high tip gap, while there is virtually no irregularity in the low tip gap region. This effect can occur in cases where the eccentricity is as low as $\varepsilon_{\max }-\varepsilon_{\min }=10 \% \bar{\varepsilon}$, where $\varepsilon$ is the tip gap size [8]. The BLI fan has a relatively large tip gap, which is expected to increase sensitivity to eccentricity in the distorted flow results. In addition, the individual pressure transducers have slightly different sensitivity to disturbances. Note that this eccentricity also affects the clean flow results. In Figure 7 and Figure 9 a circumferential position was chosen where the eccentricity is small to give smaller disturbances in the signals prior to stall.

To isolate the effects of BLI on stall it was therefore necessary to decouple the BLI distortion from these other sources of non-axisymmetry. At $N S_{d}, 36$ independent sets of measurements were recorded with the distortion gauze rotated by $10^{\circ}$ each time. In this manner the distortion is decoupled from the other sources of non-uniformity, which remained stationary for all of these measurements. The aim was then to eliminate the effects of these factors by averaging the results. Individual results are plotted as small crosses in Figure 13 and their averages are shown as solid lines. 

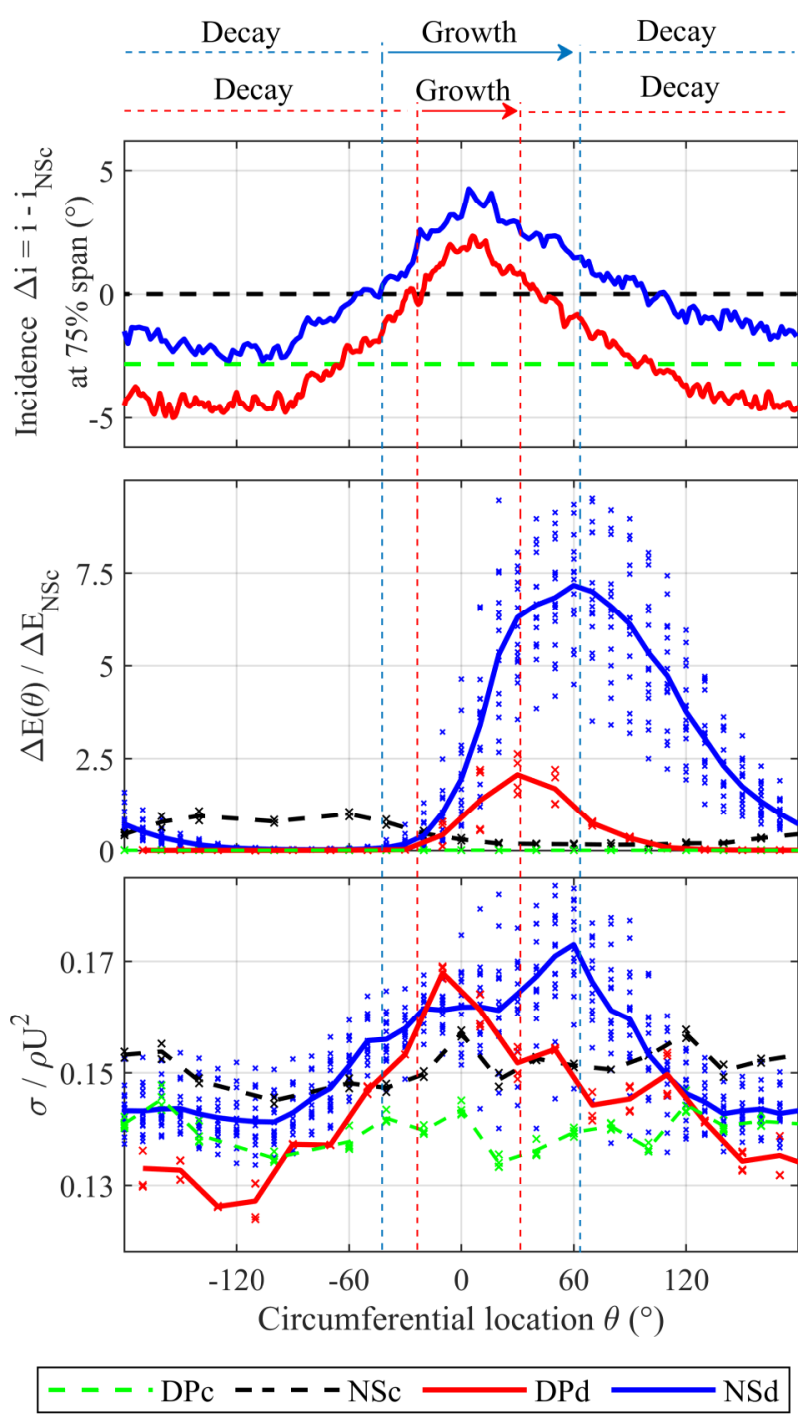

Figure 13 - Comparison of the incidence relative to the $N S_{c}$ incidence level, disturbances energy and the signals' standard deviations. Crosses show data from individual measurements, averages are shown as solid lines.

When the rig is running at $D P_{d}$, the energy level $\Delta E(\theta)$ plot is approximately symmetric with $\theta \approx$ $30^{\circ}$ as the line of symmetry. The peak intensity is about 2 times larger than the maximum level at $N S_{c}$ and about $15 \%$ of the annulus area has disturbance levels larger than the critical $N S_{c}$ level. In such conditions, the rig would stall immediately if it was running in clean flow. However, the distorted flow conditions limit the growth of any critical disturbances and stall inception is prevented. At $N S_{d}$, the energy levels are higher and the average peak is 7 times larger than the maximum energy level at $N S_{c}$. 
The proportion of the annulus operating with disturbance levels higher than the $N S_{c}$ critical level is greater than $50 \%$.

To relate the steady flow incidence to the energy function $\Delta E$, the regions of growth and decay are indicated. The region of growth is defined as where disturbances increase in amplitude, i.e. $\mathrm{d}(\Delta E) / \mathrm{d} \theta>$ 0 , whereas the decay region is the region in which any disturbances are suppressed or are not present. This is labelled using blue/red dashed lines in Figure 13. Starting at $\theta=-40^{\circ}$, the disturbances at $N S_{d}$ start to grow. This matches the position where the incidence level increases above the $N S_{c}$ value. The growth rate gradually increases as does the incidence at the corresponding circumferential location. Both quantities peak at a similar location and a drop in the incidence level results in the drop of the growth rate. When the incidence drops below the $N S_{c}$ level, the magnitude of $\Delta E$ falls away rapidly. At the point when the incidence levels are very low, the driving force for decay is high, but the energy level is already close to its steady state and hence there is a disagreement in the incidence levels correlation with the decay rates. The growth and decay regions when operating at $D P_{d}$ have been determined in a similar way and it is apparent that the relation between the incidence levels and the energy in the disturbances is the same as for the $N S_{d}$ case.

The variation in the standard deviation data relates less well to the incidence levels, which is to be expected since the standard deviation includes the pressure fluctuations at all frequencies and not just disturbances relevant to instability. The results at $D P_{c}$ and $N S_{c}$ show that the standard deviation is increased when the fan is close to stall and the incidence level is higher. In these clean flow cases, the standard deviation is not independent of location and this is likely to be due to variations in tip gap size around the annulus and differences in the probe sensitivities. However, the total circumferential variation at these conditions is only $8 \%$ of the mean value. At $D P_{d}$ and $N S_{d}$ the standard deviation is clearly increased in regions of high rotor incidence and reduced in the low incidence region, but there is no clear alignment between the plots. The circumferential variation in standard deviation is $56 \%$ of the mean value at $D P_{d}$ and $40 \%$ of the mean value at $N S_{d}$. 


\section{LINKING THE 3D FLOW-FIELD TO STALL}

In the previous section, the disturbance growth and decay were linked to the incidence levels at $75 \%$ span. Here the steady-state three-dimensional flow field leading to this incidence variation is considered in more detail and the relationship of the flow features to circumferential regions of disturbance growth and decay are explored.

The rotor incidence is governed by the axial velocity and swirl angle distributions at rotor inlet. With BLI inlet flow, these are non-uniform in both the radial and circumferential directions as shown in Figure 15 and Figure 14.

Considering firstly the design point, $D P_{d}$, the axial velocity field resembles that measured further upstream in Fig. 2. The lowest momentum fluid lies at the bottom of the duct and is responsible for the destabilising positive incidence peak in Fig. 13. However, the peak-to-peak velocity variation in Figure 15(a) is considerably reduced compared with Fig. 2 due to a redistribution of mass flow between stations 1 and 3. The rotor induces a non-uniform static pressure field in response to the distortion. The pressure gradients create a 3D swirling flow upstream of the rotor, seen in Figure 14(a), leading to regions of positive and negative swirl at rotor inlet. The overall effect of the 3D flow is to drive mass from the high-momentum to the low-momentum part of the annulus and this promotes stability by reducing the magnitude of the incidence variation. Further details of the flow physics involved can be found in [24].

The resulting rotor incidence distribution is shown in Figure 16(a). Here the incidence is plotted relative to the critical value in clean flow in the same manner as Fig. 13. In addition, arrows have been sketched around the circumference. These mark the regions of growth and decay of disturbance energy $\Delta E$ from Fig. 13. These are observed to match closely with regions where the incidence is above or below the critical clean flow value respectively. Furthermore, the highest growth rate is observed in the region where the incidence level is highest in both intensity and spatial spanwise extent. In contrast, the regions of the lowest disturbances levels correspond to areas of the annulus where the incidence is less than the level at $N S_{c}$ and comparable to the clean flow value at $D P_{c}$. The contour plot highlights the fact 
that at the design point, the majority of the annulus area lies below the critical clean flow incidence value, which promotes stability despite the region of above-critical incidence at the bottom.

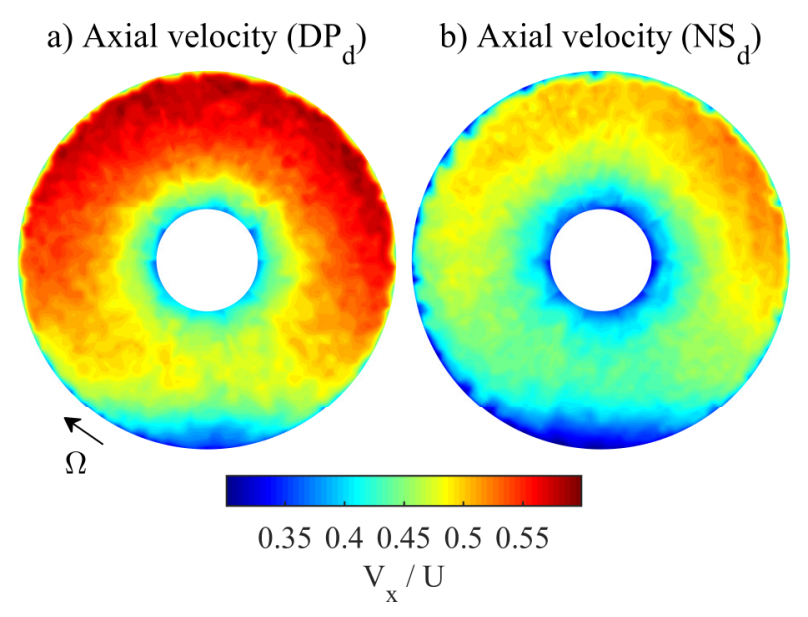

Figure 15 - Axial velocity contours (station 3)

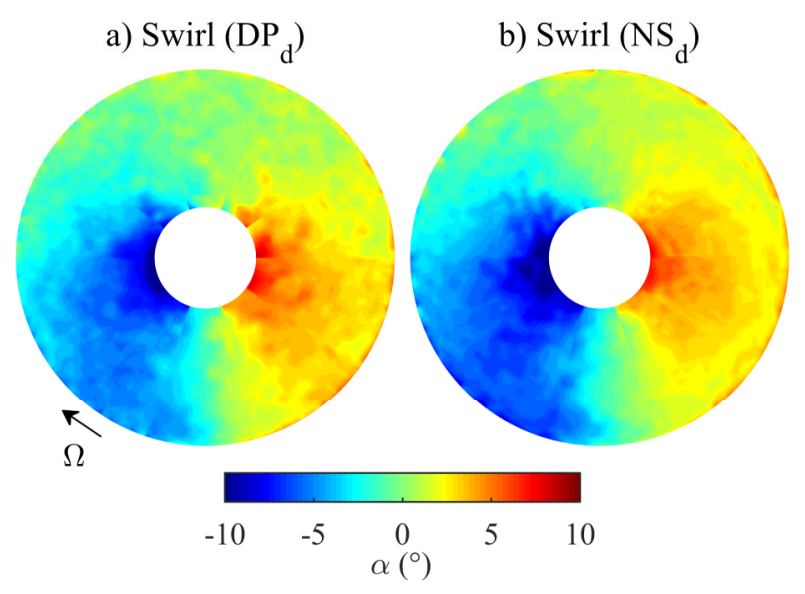

Figure 14 - Absolute swirl angle upstream of the rotor (station 3)

At the near-stall condition, $N S_{d}$, the average incidence was observed to increase relative to $D P_{d}$, which is shown in Figure 16. Figure 15(b) and Figure 14(b) show that this is predominantly due to a decrease in the average value of axial velocity, as the shape and magnitude of the non-uniform swirl distribution does not change significantly between the two operating points. This shows that there is no significant change in the bulk flow physics of the fan-distortion interaction at the near-stall operating point. The incidence variation in Figure 16(b) therefore has a similar form to that in the design point in Figure 16(a). The average value of incidence has therefore increased and, most importantly, the regions of incidence above the critical clean flow value have increased in both circumferential and spanwise Copyright $(\subset) 2015$ by ASME 
extent. Again, the previously observed regions of growth and decay agree well with this incidence pattern.

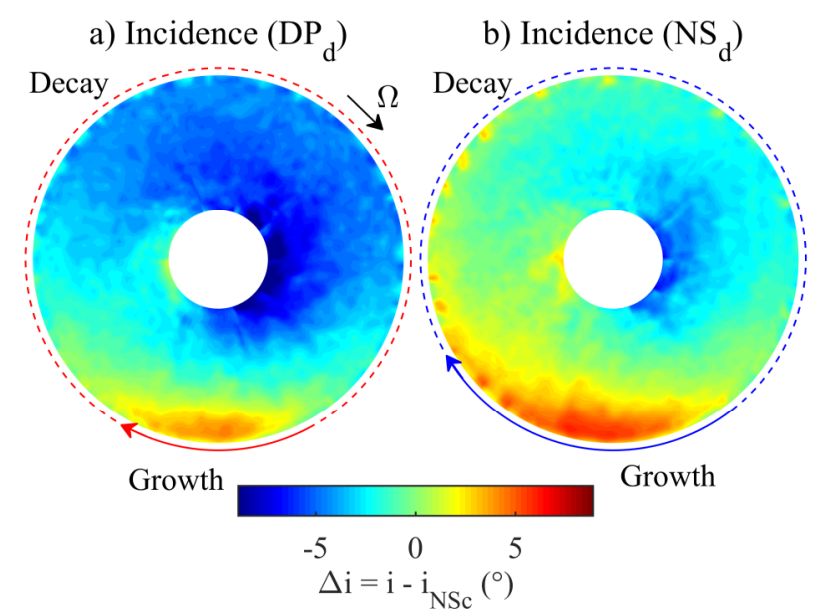

Figure 16 - Incidence relative to incidence at $N S_{c}$ (station 3)

A stall event, shown in Figure 17a, is used to illustrate the unsteady development of a stall cell in distorted flow. The front and the rear of the stall cell have been identified in each of the sixteen signals from the extent of the perturbations. The stall cell size has then been determined from the circumferential arc length from the front to the rear of the cell at each time instant. This is as indicated in Figure $17 \mathrm{a}$.

The resulting stall cell size as a function of time is plotted in Figure 17c. This shows that the extent of the stall cell goes through several cycles of growth and decay before settling down to a size of approximately $180^{\circ}$. The stall cell behaviour during one such cycle is illustrated in Figure $17 \mathrm{~b}$. This schematic shows the stall cell size and location, based on the results in Figure 17c, at four instances in time.

Initially, at time $t=42 \mathrm{rev}$, a stall cell starts to grow in the region where the incidence is above the critical level. At time $t_{1}$ and $t_{2}$ this cell is growing as the front of the stall cell is in a region where the incidence exceeds the critical value and the rear of the cell moves slowly while it propagates through the low momentum region. At time $t_{3}$, the cell front has reached the top of the annulus, where the incidence drops below the critical level and its speed decreases. The stall cell starts to shrink as the rear of the cell starts to catch up with the front. The cell size is a minimum at time $t_{4}$, when the cell front reCopyright $(\subset) 2015$ by ASME 
Journal of Turbomachinery

enters the low momentum region. The cycle repeats until a fully developed stall cell is established after 6 to 8 rev.

The mechanism illustrated in Figure $17 \mathrm{~b}$ is supported by the data shown in Figure 17c. Ticks on the y-axis are chosen to show the region of higher than critical incidence. The gradients of the curves, $d \theta / d t$, in Figure 17c indicate the propagation speed of the front and rear of the stall cell. For the first four cycles, the plots indicate that the front of the stall cell moves through the region of elevated incidence at a higher speed than average and that the rear moves more slowly. Outside the high incidence region, the opposite is true and the stall cell shrinks. The stall cell is smallest in size in each cycle just before the front re-enters the region of increased incidence. In the stall event shown, by the fifth cycle, the stall cell is fully developed and does not change in size and speed further. 
(a)

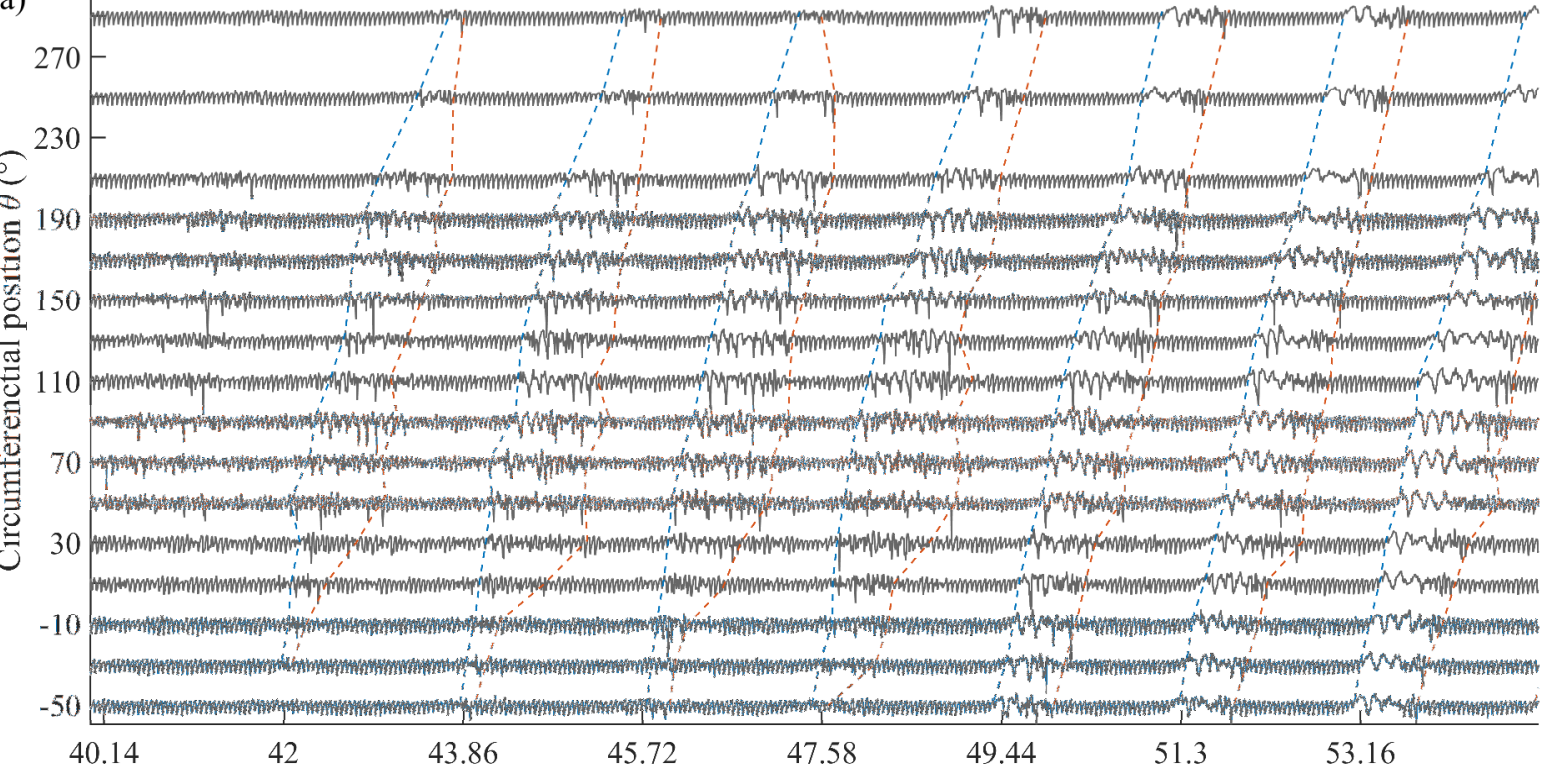
40.14
42
43.86

Time (rev)

(b)
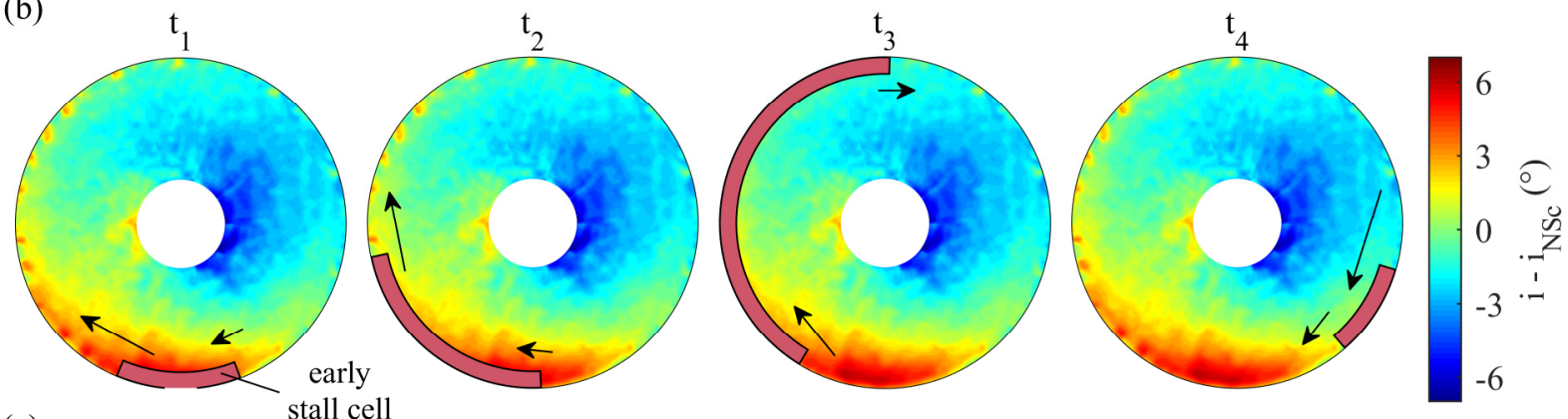

(c)

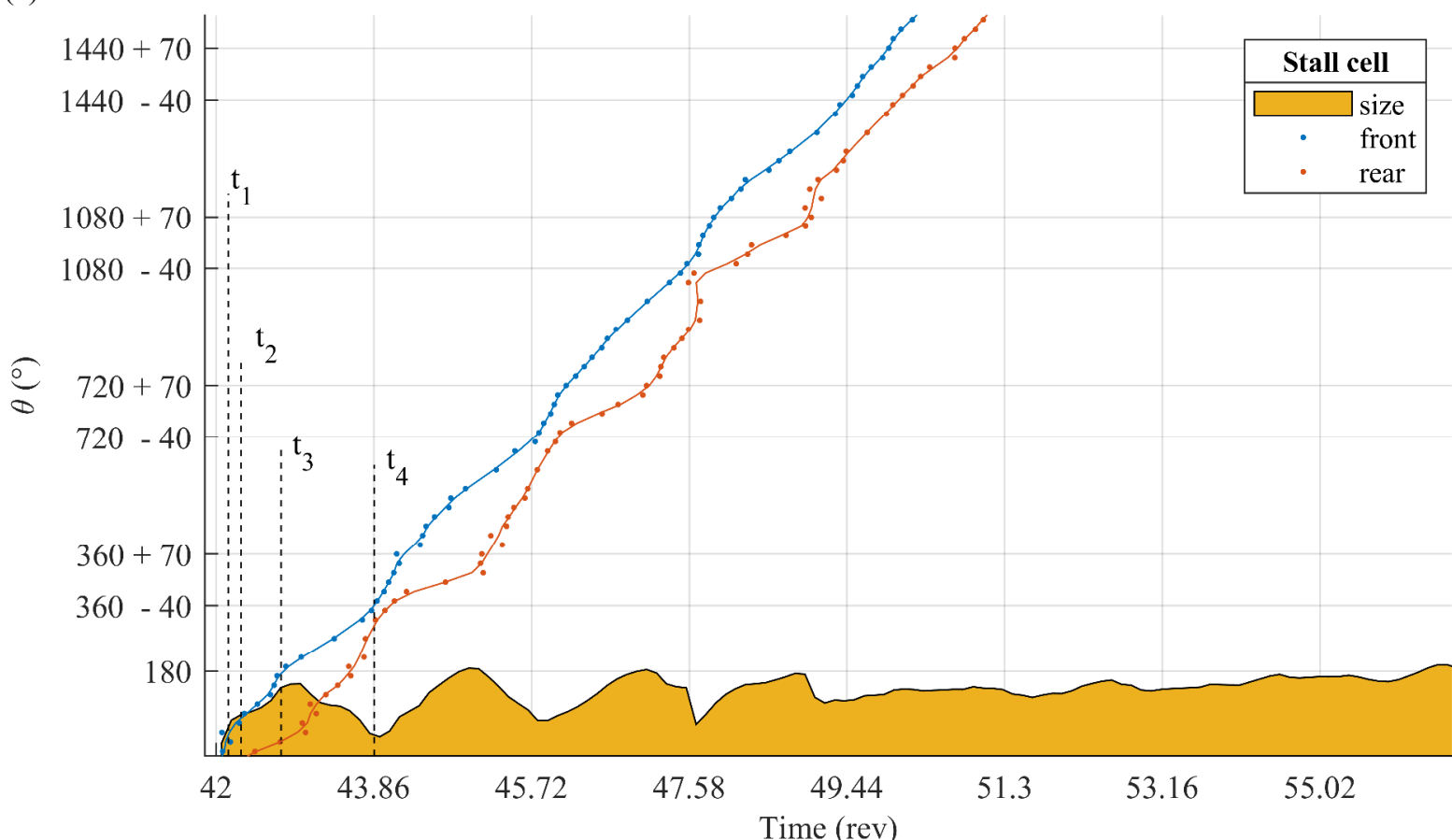

Figure 17 - Stall cell development, waveforms (a), schematic of early stall cell propagation (b), stall cell size as a function of time (c)

Copyright (C) 2015 by ASME

Perovic, TURBO-19-1031 
Figure 18 shows contours of axial velocity measured downstream of the fan rotor at station 4 . Again, results in distorted flow at both $D P_{d}$ and $N S_{d}$ are included. This figure indicates the circumferential and spanwise extent of flow separations within the blade tip region. Note that the precise size of the separations in the spanwise extent will be dependent on the size of the tip gap, which is relatively large in this fan. This would be smaller if the tip gap were smaller, but the same conclusions hold regardless of tip gap size. Note that these are steady-state time-averaged measurements and therefore will not correlate exactly with the measurements of unsteady fluctuations. In addition there is expected to be a shift of circumferential regions of growth and decay by approximately $10^{\circ}$ in the positive theta-direction relative to Figure 16 due to particle displacement of the swirling flow [24].

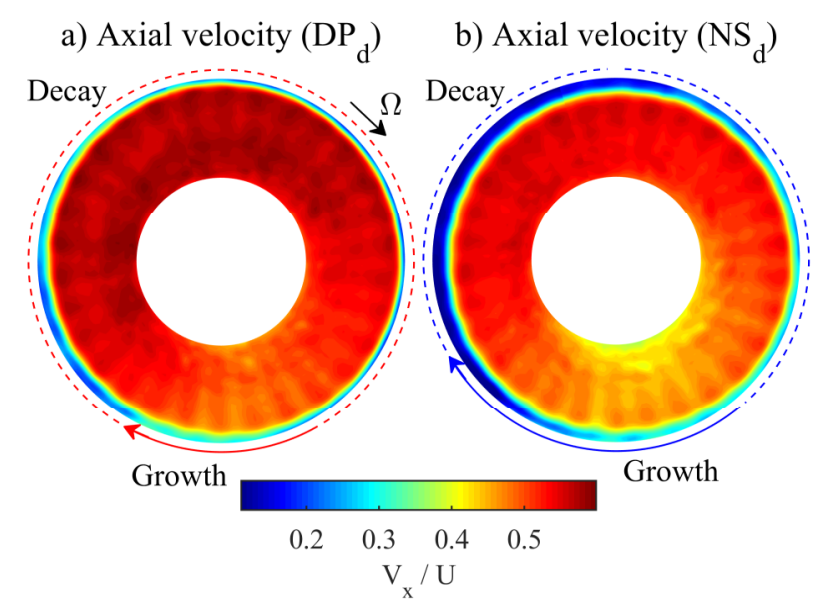

Figure 18 - Axial velocity downstream of the rotor (station 4)

Figure 18 shows that the growth and decay regions correspond with regions in which the tip flow separations increase and decrease in radial size. As the blades enter the growth region, the extent of flow separations starts increasing and continues to do so throughout the growth region. When the decay region is entered, the separation size initially remains constant then decays at a rate that appears to correlate with the negative tip relative incidence in Figure 16. The variation in the separation therefore matches up well with incidence, but does not follow the fall off in disturbance energy observed in Figure 13 for $60^{\circ}<\theta<180^{\circ}$. This is to be expected since there will be some time lag in the propagation and recovery of the separated tip flow. As shown in [24] the tip separation is a result of high incidence combined with the high tip clearance causing the casing boundary layer to locally detach. The precise 
relationship between this separation and the disturbances causing stall will be investigated in future research.

\section{CONCLUSIONS}

1) The reduction in stability margin caused by BLI for the fan studied is found to be small (1$2 \%$ of flow coefficient).

2) With BLI distortion a fan can operate stably despite the presence of local regions where the rotor operating point lies well beyond the clean flow stability boundary.

3) With BLI distortion applied, the measured incidence onto the fan rotor varies around the annulus due to non-uniform upstream swirl and velocity. The growth and decay of disturbances that lead to stall are found to correspond directly to the variation of incidence in the rotor tip region.

4) The disturbances in casing static pressure relevant to stall inception occur at frequencies below the blade passing frequency. These disturbances grow in regions where the incidence at the tip is above the incidence required for stall in clean flow. In regions where the tip incidence is lower, the disturbances are found to rapidly decay.

5) Stall with BLI is found to occur when disturbances that are initiated in the region of lowmomentum fluid are able to propagate around the entire annulus, without decaying completely in the region of high momentum fluid. This requires a large enough fraction of the annulus to exceed incidence levels that are capable of initiating, growing and sustaining disturbances.

\section{ACKNOWLEDGMENTS}

The authors are grateful to a large team at Rolls-Royce for their insight into the work, coordinated by Lorenzo Raffaelli. Paul Hield is thanked for his feedback. At the Whittle Laboratory, Ivor Day, Anna Young and Graham Pullan are thanked for their comments on early versions of this work. Colin Bullman is also thanked for supporting the experimental rig tests. 


\section{NOMENCLATURE}

\section{Symbols}

E

Pressure

$\phi \quad$ Flow coefficient

$\psi \quad$ Stage loading

$t \quad$ Time

$U \quad$ Blade velocity at mid-span

$f \quad$ Frequency

$\Omega \quad$ Shaft angular velocity

$\omega \quad$ Rotating stall cell angular velocity

$\theta \quad$ Circumferential location

$\alpha \quad$ Absolute swirl angle

$i \quad$ Incidence

$V \quad$ Velocity

$\rho \quad$ Air density

Re Reynolds number

M Mach number

$\sigma \quad$ Standard deviation

Abbreviations

$\begin{array}{ll}D P & \text { Design operating point } \\ N S & \text { Near stall operating point } \\ \text { rev } & \text { Rotor revolution }\end{array}$

\section{Subscripts}

$\begin{array}{ll}c & \text { Clean flow } \\ d & \text { Distorted flow } \\ b p & \text { Blade passing } \\ x & \text { Axial direction } \\ s & \text { Sampling } \\ t & \text { Total } \\ t s & \text { Total to static } \\ \text { rel } & \text { Relative } \\ \text { atm } & \text { Atmospheric }\end{array}$

Superscripts

$\begin{array}{ll}- & \text { Time average mean } \\ \text {, } & \text { Fluctuation }\end{array}$

\section{REFERENCES}

[1] Felder, J. L., Brown, G. V., Kim, H. D. and Chu, J. (2011), "Turboelectric Distributed Propulsion in a Hybrid Wing Body," in 20th ISABE Conference, Gothenburg, ISABE-2011-1340.

[2] Hall, C. A., Schwartz, E. and Hileman, J. I. (2009), "Assessment of Technologies for the Silent Aircraft Initiative," Journal of Propulsion and Power, 25(6), pp. 1153-1162.

[3] Uranga, A., Drela, M., Greitzer, E., Titchener, N., Lieu, M., Siu, N., Huang, A., Gatlin, G. and Hannon, J. (2014), "Preliminary Experimental Assessment of the Boundary Layer Ingestion Benefit for the D8 Aircraft," 52nd AIAA Aerospace Sciences Meeting, National Harbor, Maryland, AIAA 2014-0906.

[4] Smith, L. H. (1993), "Wake Ingestion Propulsion Benefit," Journal of Propulsion and Power, 9(1) pp. 7482.

[5] Day, I. J. (1993), "Stall Inception in Axial Flow Compressors," Journal of Turbomachinery, 115(1) pp. 1-9. 
[6] McDougall, N. M., Cumpsty, N. A. and Hynes, T. P. (1990), "Stall Inception in Axial Compressors," Journal of Turbomachinery, 112(1) pp. 116-123.

[7] Weichert, S. and Day, I. J. (2014), "Detailed Measurements of Spike Formation in an Axial Compressor," Journal of Turbomachinery, 136(5), p. 051006.

[8] Young, A. M., Day I. J. and Pullan, G. (2013), "Stall Warning by Blade Pressure Signature Analysis," Journal of Turbomachinery, 135(1), p. 011033.

[9] Inoue, M., Kuroumarau, M., Tanino, T., Yoshida, S. and Furukawa, M., (2001), "Comparative Studies on Short and Long Length-Scale Stall Cell Propagating in an Axial Compressor Rotor," Journal of Turbomachinery, 123(1), pp. 24-32.

[10] Pullan, G., Young, A. M., Day, I. J., Greitzer, E. M. and Spakovszky, Z. S. (2015), “Origins and Structure of Spike-Type Rotating Stall," Journal of Turbomachinery, 137(5), p.051007.

[11] Bennington, M. A., Ross, M., Cameron, J., Morris, S., Du, J., Lin, F., and Chen, J. (2010), “An Experimental and Computational Investigation of Tip Clearance Flow and its Impact on Stall Inception," in Proceedings of ASME Turbo Expo 2010, Glasgow, United Kingdom, GT2010-23516.

[12] Katz, R. (1958), "Performance of Axial Compressors With Asymmetric Inlet Flows," PhD Thesis, California Institute of Technology, Pasadena, California.

[13] Reid, C. (1969), "The Response of Axial Flow Compressors to Intake Flow Distortion," in Proceedings of the Gas Turbine Products and Conference Show, Cleveland, Ohio, 69-GT-29.

[14] Williams, D. D. (1986), "Review of Current Knowledge of Engine Response to Distorted Inflow Conditions," AGARD CP-400, Engine Response to Distorted Inflow Conditions, Munich, pp. 1-1-1-32.

[15] Longley, J. P. and Greitzer, E. M. (1992), "Inlet Distortion Effects in Aircraft Propulsion System Integration," AGARD LS-183, "Steady and Transient Performance Prediction of Gas Turbine Engines", pp. 6-1-6-18.

[16] Pearson, H. and McKenzie, A. B. (1959), "Wakes in Axial Compressors," Journal of the Royal Aeronautical Society, pp. 415-416.

[17] Hynes, T. P. and Greitzer, E. M. (1987), “A Method for Assessing Effects of Circumferential Flow Distortion on Compressor Stability," Journal of Turbomachinery, 109(3), pp. 371-379.

[18] Longley, J. P. (1990), "Measured and Predicted Effects of Inlet Distortion on Axial Compressors," in Proceedings of ASME Turbo Expo 1990, Brussels, Belgium, 90-GT-214.

[19] Shaw, M. J., Hield, P. and Tucker, P. G. (2013), "The Effect of Inlet Guide Vanes on Inlet Flow Distortion Transfer and Transonic Fan Stability," Journal of Turbomachinery, 136(2) p. 021015.

[20] Yao, J., Gorrell, S. E. and Wadia, A. R. (2010), "High-Fidelity Numerical Analysis of Per-Rev-Rev Type Inlet Distortion Transfer in Multistage Fans," Journal of Turbomachinery, 132(4), p. 041014.

[21] Jerez Fidalgo, V., Hall, C. A. and Colin, Y. (2012), “A Study of Fan-Distortion Interaction Within the NASA Rotor 67 Transonic Stage,” Journal of Turbomachinery, 134(5), p. 051011.

[22] Mistry, C. S. and Pradeep, A. M. (2013), "Investigations on the Effect of Inflow Distortion on the Performance of a High Aspect Ratio, Low Speed Contra Rotating Fan Stage," in Proceedings of ASME Turbo Expo 2013, San Antonio, Texas, GT2013-94311.

[23] Florea, R.V., Voytovych, D., Tillman, G., Stucky, M., Shabbir, A., Sharma, O. and Arend, D.J. (2013), "Aerodynamic Analysis of a Boundary-Layer-Ingesting Distortion-Tolerant Fan," in Proceedings of ASME Turbo Expo 2013, San Antonio, Texas, GT2013-94656.

[24] Gunn, E. J. and Hall, C. A. (2014), “Aerodynamics of Boundary Layer Ingesting Fans,” in Proceedings of ASME Turbo Expo 2014, Dusseldorf, Germany, GT2014-26142.

[25] Madani, V. and Hynes, T.P. (2009), "Boundary Layer Ingesting Intakes: Design and Optimization," in Proceedings of XIX International Symposium on Air Breathing Engines, ISABE 2009-1346. 